\title{
Cochlear Implants and the Right to Language: Ethical Considerations, the Ideal Situation, and Practical Measures Toward Reaching the Ideal
}

\author{
Tom Humphries ${ }^{1}$, Poorna Kushalnagar2 ${ }^{2}$, Gaurav Mathur ${ }^{3}$, \\ Donna Jo Napoli ${ }^{4}$, Carol Padden ${ }^{1}$, Christian Rathmann ${ }^{5}$ and Scott Smith 6 \\ ${ }^{1}$ University of California at San Diego \\ ${ }^{2}$ Rochester Institute of Technology \\ ${ }^{3}$ Gallaudet University \\ ${ }^{4}$ Swarthmore College \\ ${ }^{5}$ Universität Hamburg \\ ${ }^{6}$ University of Rochester \\ 1,2,3,4,6USA \\ ${ }^{5}$ Germany
}

\section{Introduction}

Cochlear implants (CIs) in small children who do not yet have a firm footing in first language acquisition are an on-going experiment with human subjects, in the sense that the risks involved have not been properly identified, much less assessed, due to the failure to focus on the biology of language and its role in first language acquisition. Too often, the developmental cognitive milestones of the deaf child and the right to language are not considered, and we risk contributing to cases of linguistic deprivation with all the ensuing consequences. We propose an immediate remedy: to teach deaf children a sign language, along with training in speech and speech-reading. For many families, such as those that live far from a Deaf community, as in a rural situation, this presents practical problems, which we address.

\section{Background on the problem}

CIs as a rehabilitative technology to remediate hearing loss were approved before presentday information on the biology of first language acquisition was available. This mismatch of timing has led to the present problem.

\subsection{History of cochlear implants}

Research on transforming auditory information into electrical impulses that might deliver language to the brain began in the 1930s at the Military Academy in Leningrad, Russia. "Stimulating electrodes were inserted into the middle ear of patients with and without middle ear structures present" (Djourno et al., 1957, as cited in Eisen, 2000: 91). The 
disappointing results led to the rejection of the middle ear as the proper site of electrical stimulation.

In the 1950s at the Head and Neck Surgery section of the l'Institut Prophylactique in Paris, France, CIs were first developed, in which electrical stimulation was delivered to the auditory nerve. The first implant surgery was performed in 1957. Success was limited. The patient could only discriminate lower from higher frequency noises and could "appreciate environmental noises and several words, but could not understand speech" (Eisen, 2000: 91). Around 1960, American physicians attempted inserting gold wire electrodes through the skin, but local infections made this method unfeasible. In 1964, an electrode was implanted into the modiolus (the central axis of the cochlea) of a deaf patient at Stanford University Hospital. The potential for such an implant to deliver language was reported as "discouraging" (Simmons, 1966, as cited in Eisen, 2000: 92). Meanwhile, others elsewhere in California were implanting single electrode devices. Over the next decade, the attitude of the medical world was cautionary, but the concerns were about whether CIs would yield useful hearing. Importantly, the concerns were not about whether a CI could harm a patient.

In 1975, the National Institutes of Health sponsored an evaluation of thirteen patients who had been implanted with single-channel devices. They concluded that these devices "could not support speech understanding" but did support speech skills such as voicing and speech-reading, and these devices did enhance quality of life (Bilger, 1977, as cited in Eisen, 2000: 92). Immediately, testing began on a cat model in California, and other researchers in both California and Melbourne, Australia, capitalized on advancements in computer technology enabling them to miniaturize the various parts of the device. In 1972, the first U.S. Food and Drug Administration-approved devices were implanted, and by the mid1980s 1000 individuals had been implanted. Of those first 1000 implant surgeries, several hundred were on children; the age criterion for use of the device was subsequently lowered from 18 years to 2 years old in 1980. In 1984, multiple channel devices (with multiple points of excitation to the cochlear nerve) were developed, and by the next year, the Food and Drug Administration approved their use in adults. In 1990, they extended their use to children as young as 2 years old, although children had been receiving these multiple channel devices in clinical trials since 1985 (Barnes, 1994). Since multiple channels "significantly boosted speech recognition performance", the push was to implant more children at a younger age (Wilson et. al., 1991, as cited in Eisen, 2000: 92). Optimism rose, and as one of the major pioneers in the development of CIs reported, "Limited open-set word and sentence recognition is possible for at least some children, perhaps as many as 30\%" (House, 1991: 718).

Over the next decade, the advent of universal newborn hearing loss screenings coupled with studies showing that earlier implantation correlates to earlier development of auditory recognition and speech comprehension (Waltzman \& Roland, 2005; Yoshinaga-Itano et al., 1998; Yoshinaga-Itano et al., 2000) resulted in more and more children being implanted at 12 months of age and even younger (Christensen \& Leigh, 2002). By 2009 approximately $80 \%$ of deaf children in developed countries were implanted, many before the age of 1 year old (Brentari, 2010). In earlier days, if a child had better residual hearing in one ear, the ear with lower residual hearing would be implanted, so that the child could continue to use whatever residual hearing was available from the unimplanted ear (Brackmann et al., 2001). These days, however, CIs have become so overwhelmingly the standard of care that many 
children are binaurally implanted, which results in loss of whatever residual hearing benefits the unimplanted ear might offer (Snow \& Wackym, 2008).

\subsection{History of knowledge about first language acquisition}

Multiple theories of language acquisition were in play in the decades before the 1990s. In 1967, Eric Lenneberg proposed that there was a language mechanism in the brain which allowed humans to acquire language naturally, without instruction, by being exposed to it. He further demonstrated that this mechanism changed over time, so that after a certain age the human brain no longer had this capacity (Lenneberg, 1967). The brain is hard-wired to acquire language, but the plasticity that allows this is lost early, around the age of five years old. This "critical-age" or "critical-period" hypothesis has since been exposed to a great deal of debate and testing. Discoveries of children who had grown up "wild", without being surrounded by human language (Shattuck, 1980), and discoveries of children who had been criminally abused to the point of being deprived of language (Curtiss, 1977), gave support to Lenneberg's hypothesis. Likewise, studies of deaf people who did not receive accessible language until after the critical period, either because they were denied hearing aids (Curtiss, 1994; Grimshaw et al., 1998) or because they were denied sign language (Mayberry \& Eichen 1991; Newport, 1990), gave support to Lenneberg's hypothesis. Still, there were controversies over the biological nature of language.

However, with the advent of neuroimaging, there is even stronger evidence for a biological foundation for language (Pakaluk \& Neville, 2010; and the references cited there). Initially, much of the work using neuroimaging was focused on language pathologies (Stemmer \& Whitaker, 2008), but over time linguists, particularly those interested in the development of deaf children, have used it in studies of first language acquisition and of second language learning (Meisel, 2011; and the references cited there).

\subsection{Summation of the problem}

We now possess evidence for the following point, which we didn't know at the time that the Food and Drug Administration, a governmental agency in the United States, and similar governmental agencies in developed countries gave approval for the implantation of CIs in children: if a person does not acquire language before the age of five, that person is greatly at risk of not becoming fluent in any human language. Such a person is linguistically deprived.

In the abstract, this knowledge does not necessarily pose a dilemma with respect to CIs. In reality, however, some children who are implanted wind up linguistically deprived. CIs can actually lead to a harm that the Food and Drug Administration in the United States as well as governmental agencies in other countries were not aware existed at the time the devices were approved. Not only does new evidence challenge the basis of the FDA's approval, a recent commission established by the FDA concluded that existing procedures for implanted devices did not protect patients and recommended that these procedures be dropped (Institute of Medicine, 2011). Recent recalls of implant devices due to technical failures, such as the Sonova Holding AB's recall of its HiRes 90K device in 2010 and the Cochlear Ltd.'s recall of its Nucleus C1500 implants in 2011, raise the likelihood of repeat surgeries for implant recipients and cast further doubt on the wisdom of doing surgeries on 
infants and small children without a strong probability (not merely a possibility) of linguistic success (Lower, 2011). We will now establish our claim that CIs pose risk of harm to deaf infants and children.

\section{Cochlear implants and linguistic deprivation}

CIs lead to linguistic deprivation in some instances. This is due to two facts. First, CIs as a standalone technology do not provide accessible language. Second, health professionals typically either advise against or do not encourage giving a sign language to an implanted child, thus cutting them off from an accessible language during the years crucial to first language acquisition. There is not enough education in fields related to medicine about sign language and its role in language development. This leads to widespread misconceptions and misinformation, and thus, poor advice to parents and practitioners.

\subsection{Variable success of cochlear implants}

While many studies have tried to assess the success of CIs, it is difficult to know exactly what these studies mean in terms of what a family with a deaf newborn or newly deafened child can expect as they make decisions about language options. The first problem is that these studies report highly variable success (Bouchard et al., 2008; Fink et al., 2007; Peterson et al., 2010; Szagun, 2008), even in studies by enthusiastic promoters of CIs (such as Gulya et al., 2010). One would hope to be able to compare studies, to glean whatever reliable information they might offer to these families. However, many cannot be compared with each other because they use different methodologies and test for different auditory functions, some of which are only minimally related to language (Bouchard et al., 2008). Further, the children tested are a heterogeneous group with respect to the age of onset of hearing loss, the age of diagnosis of hearing loss, the age of implantation, the particular device implanted, the particular surgical technique used, the amount and type of rehabilitation after surgery, residual hearing in the unimplanted ear, socio-economic status of the family, and other factors, all of which will affect outcomes (Santarelli et al., 2008). This situation leaves families in a quandary as to what to do, and health professionals are unable to advise families effectively. Indeed, parents who are face for the first time with raising a child who is deaf are likely to report a higher level of stress and depressive symptomatology (Kushalnagar et al., 2007), although the stress level is ameliorated by perceived support from early intervention professionals or other parents who have deaf children (Hintermair, 2000; Lederberg \& Goldbach, 2002; Meadow-Orlans, 1994).

In the next section, we make a strong recommendation about what families should do and about what health professionals should advise them. Here, we focus attention on one disturbing and sobering fact. While there is variability in the success rate and in standards for what constitutes success, there is agreement that some children receive no discernible auditory benefit from CIs. These children cannot distinguish speech sounds from environmental sounds, and they cannot distinguish between environmental sounds. The next group of children displaying more response to implants still do not gain linguistic benefit, but can distinguish among environmental sounds (such as distinguishing between a knock on a door and a fire alarm). The next group up gains only a minimal advantage in speech, such as being able to distinguish the number of syllables in a speech stream but not being able to distinguish words. We argue strenuously that this does not constitute 
linguistic benefit even if it involves speech units. The next group up can converse with family members and close friends, using speech-reading and context in addition to the auditory information that CIs provide. And the "stars," a term used often in the literature (e.g. David Pisoni), can converse with strangers, but they must use speech-reading and context in addition to auditory information. The numbers of children in each of these five groups is a point of controversy in the literature. A CI team (surgeon, psychologist, and rehabilitation therapist) from Alfred I. duPont Hospital for Children in Wilmington, Delaware, estimated that these groups were roughly equal in size (in a discussion at Swarthmore College in 2006). Multiple studies demonstrate that children implanted earlier, all other factors being equal, do better than children implanted later ( $\mathrm{O}^{\prime}$ Reilly et al., 2008, among many), hence the more recent practice of implanting children at twelve months or even earlier. But even children implanted early have a highly variable range of success. Additionally, initial gains in speech production and perception, as indicated through performance in hearing settings, are not maintained as children progress in school (Marschark et al., 2007). Websites of hospitals that perform CI surgery often report that they have "high success" rates, and websites that promote CI surgery often report that the "majority" of users are satisfied, but percentages are not given, and clear guidelines for what counts as success are elusive. Further, most of the evidence cited by these websites involve individuals who were implanted after the critical period. These websites do not give reliable statistics on children who rely on CIs for first language acquisition. The aspirations and expectations of deaf adults are quite different from those of a family who is considering implanting a small child and relying on the implant for first language acquisition.

As scientists who read CI literature and who are specialists in deaf matters, we suggest that a conservative estimate of the number of children who do not get enough linguistic input from CI usage to ensure acquisition of a first language is $20 \%$, even assuming that the overall record has improved in recent years. We suspect the real percentage of lack of benefit is actually higher. In a study of more than 20,000 children implanted since 2000, 47\% of them do not use their CIs (Watson \& Gregory, 2005). Reported reasons for nonuse included lack of language satisfaction in addition to other reasons such as severe pain from the sounds and equipment, facial twitching, postsurgery scarring, and feelings of stigma. The human drive to communicate with others is so strong that if these children had actually found satisfaction in their linguistic abilities with the implants, we fully expect that most would not have stopped using them. There is a dearth of information about the experiences and language satisfactions of people with CIs (Valente, 2011), and those few people who do step forward to detail their experience (such as Snoddon, 2005) may find themselves the target of insult and ridicule for saying anything negative about CIs (Valente, 2011). The public's cultural belief in technology and its restorative powers make it difficult for many to risk telling their stories.

While an educated estimate of the true benefit of CIs is nothing more than that, we note two important facts. First, the burden should be on the promoters of CIs to provide reliable and understandable figures regarding success. In the absence of such information, we have stepped forward. Second, even if one argues that the failure rate is much lower, such as $5 \%$, taking the risk that $5 \%$ of small children who are implanted will not get accessible language during the critical period and thus risk being linguistically deprived is unconscionable.

Many are unaware of this ethically problematic variability, or they dismiss it. Some people are optimistic about what CIs can do for the deaf child now; Stuart Blume gives a 
particularly telling account of his struggle to make language choices for his deaf son and the many positive things he was told about CIs being a "cure" for deafness, so much so that failure to implant a deaf child was considered a denial of best medical care by some (Blume, 2009). Others are optimistic that additional studies will clarify the rate of success of CIs (always in a context of consideration of multiple factors) so that families can make better informed decisions (indeed, an upcoming issue of the International Journal of Otolaryngology will be devoted to the "pearls and perils" of CIs). Still others suggest that the technology of CIs is improving so drastically that soon they will be so effective that the issue will become moot; on many websites we can read about CIs "curing" deafness, leading to a strong counter-response from members of the Deaf community fearing that such aspirations will lead to sign language becoming extinct and Deaf culture disappearing as CIs improve (a typical, if distorted, discussion is in Young, 2002).

Many present researchers, like us, take a more sober view of what technological improvements can accomplish. In describing advances up till now, Shannon et al. (2010: 369) write, "... technological advances may be nearing the point of diminishing returns, given the high costs involved and limited additional benefits they may provide. The next phase of improvement in CI performance may come not from further development of the implant hardware, but from understanding how implant speech processors may be more effectively programmed and customized for individual patients, so that the capabilities that are already available may be fully utilized."

This statement bears close reading, for it focuses our attention on an important fact: CIs are not computers. Computers sit on our desks and we instruct them what to do, and as technology improves, we can tell them more and more things to do. CIs are a different kind of technology. The implant device may add improvements but, unlike the processing power of a computer that we all consider beneficial, an improved implant device is unlikely to make substantial difference because the issue is getting the brain to interpret the input appropriately. Simply put, CIs do not hear. What they do is deliver electrical impulses directly to the cochlear nerve, bypassing the ordinary hearing channels of the ear. But the brain, which is hard-wired to receive auditory information that comes to us via the ear channels, is not hard-wired to interpret the electrical impulses that CIs deliver. That is why implanted people need "rehabilitation" (actually, training) following CI surgery. That rehabilitation goes on for years and years. In fact, long term users of CIs find that they must return to rehabilitation for a brush-up every so often. Kisor (1990: 166), who is what we call a "star" CI user, when describing what happens after his rehabilitative therapy, writes, "For more than a year, sometimes two, strangers will [come to] understand what I say the first time I say it at our first meeting, the benchmark by which I judge my speech." This benchmark should shatter ideas that functioning well in a hearing environment with a CI is easy. Many CI users cannot achieve the level of performance Kisor describes. Importantly, many hearing aid users (and non hearing aid users, for that matter) can surpass it, using an older technology.

The brain is complex, and hearing is complex. There is no reason to expect a quick and huge rise in success of CIs from an advance in technology. In any case, we must deal with the technology we presently have.

\subsection{Strictly aural input}

Many health care professionals advise against offering an implanted child a sign language (Krausneker, 2008; Lane, 2005; Lane \& Grodin, 1997; Zimmerman, 2009) and instead urge 
therapies using aural input only, such as verbal-auditory therapy (AVT, as in Estabrooks, 2006 and earlier, evaluated in Rhoades, 2006). Sign language is turned to as a last resort when all else fails (Johnston, 2006). This view possibly derives from aural-oral only proponents' belief that with cochlear implants the aural-oral approach is much more effective then ever before and that sign language is not a place to expend valuable time and energy for the child, parents, or therapists. This may also be due to the fear that sign language use will interfere with oral language skills and/or that sign language is not perceived as a bona fide language so it cannot give the child the rich cognitive input necessary for language development.

The problem with this is that it still relies on a hope that the aural-oral environment and the CI technology will provide the language development that is crucial to the child's whole future. It does not consider the risk that the CI will not enhance an already risky approach.

The fears about sign language are unfounded. Deaf children who sign gain advanced language skills which they can then apply toward understanding spoken and written language (Dockrell \& Messer, 1999), which may be why, among deaf children, a factor that correlates most reliably with good literacy skills is good signing abilities (Chamberlain \& Mayberry, 2008; Fischer, 1998; Hoffmeister, 2000; McGuinness, 2005; Strong \& Prinz, 2000; Wilbur, 2008; among many). Further, deaf children who sign identify themselves as being more confident and happy than deaf children who do not sign (Plaza Pust \& Morales López, 2008; among many). In a recent quality of life study of 231 youths with mild to profound hearing loss, youths who used speech only as their preferred mode of communication were significantly more likely to report greater stigma associated to their hearing loss than youths who used a combination of speech and sign language (Kushalnagar et al., 2011). A similar conclusion was reported in a qualitative study of Australian children and adolescents with CIs (Punch \& Hyde, 2011). Repeatedly, we find in the literature that when deaf people raised orally learn to sign as adults, they report unprecedented feelings of strong self esteem and an end to the psychological distress of having to constantly struggle at communication (Gao, 2007; Holte \& Dinis, 2001; Restuccia, 2010). This suggests that the inclusion of sign language ability in deaf children's lives is beneficial and important for healthy development and overall well-being.

With respect to the second fear, sign languages have been found definitively to be natural human languages with all the complexity (including phonology, morphology, syntax, semantics, pragmatics and discourse considerations) and expressive potential as spoken languages (see a multitude of articles in many books (such as Brentari, 2010; Mathur \& Napoli, 2010) and linguistics journals, including Sign Language \& Linguistics and Sign Language Studies, particularly many on language acquisition (such as Chamberlain et al., 2000; Meier \& Newport, 1990; Morgan \& Woll, 2002; Petitto \& Marentette, 1991), language processing (such as Emmorey, 2001), neurolinguistics (such as Neville, 1995; Poizner et al., 1987), second language learning (such as Newport, 1990), and sign literature (such as Sutton-Spence \& Napoli, 2009)). The small child who, upon being diagnosed with a hearing loss, is exposed to a sign language with frequency and regularity, where good models of the language interact with the child, will acquire that language with full competency in all the language areas that hearing children have competency in - simply in a different modality (Schick et al., 2006).

In sum, there is no justification for advising children with CIs not to learn a sign language. 


\subsection{Harm done by cochlear implants}

Any surgery involves risks, and CI surgery is no exception, where complications include infection, necrosis, injury during surgery to the facial nerve, post-surgical complications such as vertigo, meningitis, cerebrospinal fluid leakage, perilymph fluid leak, and tinnitus (Cohen \& Roland, 2006; FDA, 2011; Steenerson et al., 2001; Walker, 2008). Further, residual hearing in the implanted ear is lost with many apparati, a significant harm since hearing loss is rarely total (Mogford, 1993), although new hybrid CIs stimulate only the basal end of the cochlea where the high frequency hearing has deteriorated, preserving the residual lowfrequency hearing (Turner et al., 2007). Additionally, when the apparatus fails, a new surgery with repeated risks is called for (Borkowski et al., 2002). These risks are discussed elsewhere and we will not go into them further here since they are outside our focus.

Our focus is on language and cognitive development, an area where CI failure occurs in a significant percentage of children. Regardless of the exact percentage, every study we know of identifies failures and since this kind of failure is so destructive of the overall wellbeing of the child, this is ethically unacceptable. The advice of many health professionals to keep deaf children away from sign language compounds the problem. Since children are being implanted earlier and earlier, and more are receiving binaural implants (Snow \& Wackym, 2008; Tyler et al., 2010), those who are not learning sign language often receive far too little linguistic input during the critical years of first language acquisition. We cannot put deaf children at risk of linguistic deprivation or even language delay. Furthermore, linguistic deprivation causes other disorders, since various cognitive functions depend upon first language acquisition, including the organization of memory (Ronnberg, 2010) and the manipulation of symbols (MacSweeney, 1998). Related are psychological harms; even the child who manages minimally well with a CI can experience psychosocial problems, e.g. identity issues, in the absence of sign language knowledge (Ramsey, 2000, among many).

CIs are an experiment with human subjects that is not protecting those subjects from a foreseeable and irreversible harm. This harm has the potential to isolate them in a drastic way from other people. Ethicists have presented the moral imperative to protect a child's right to an "open future" and to protect a child's "potential autonomy" when arguing Deaf parents should not have the right to genetically screen to ensure the birth of a deaf child; just so, these same arguments apply exactly here: deliberately putting a child in a position where she may have only limited options counts as a moral harm (Davis, 1997; Feinberg, 2007). Implantation should not continue until there is agreement about pairing implants with sign language in young children, and about the appropriate age for implantation beyond which it poses no risk of harm to language acquisition or cognitive development.

\section{The remedy: Sign language}

CIs have allowed many to function better (and sometimes very well) in a hearing environment, and being able to function in a hearing environment expands a deaf person's professional and personal opportunities. While we recognize this as an important part of the deaf person's life, the priority should be to ensure that the deaf child meets typical language and cognitive development milestones, as we have discussed. This is a medical concern. Without first language acquisition, children are at risk for language delay and associated cognitive difficulties, both having negative impact on psycho-social health. 
Because of the initial failure to recognize the existence of the biological linguistic mechanism and the import of the critical period to language acquisition, the CI experiment began and gained momentum, so that it has been allowed to proceed without heed of some of the ethical principles for medical research involving human subjects. The technology developed faster than our understanding of first language acquisition. The result is that the linguistic rights and the cognitive health of deaf children have not been protected. Many implanted children fail to achieve fluency in receptive and expressive spoken language, and by the time lack of competence is recognized in the child, the child is past the critical period. Thus justice in human subjects research has not been ensured.

We offer an immediate remedy. Language is a human right. In order to protect that biological, cognitive, and psycho-social right, every deaf child should be raised with language that is completely accessible. Sign language is accessible to any deaf child (tactilely to the child who is both deaf and blind). This remedy does not exclude oral/aural training, however. Children with hearing aids and/or CI who do well at voicing and processing information received aurally will then be bilingual - a positive outcome. Children with hearing aids and/or CI who do not do well at voicing and processing information received aurally will nevertheless be assured of language acquisition, which is a prerequisite to many other cognitive activities like reading and which will assure them the right to participate in human activities that go forward largely via language, including self-expression, making friends, and fruitful employment. Given the present failure of CI to ensure fluency in a spoken language, providing access to sign language is a conservative approach that protects the right to language and is thus the morally just approach.

Raising a deaf child with a sign language when the parents are hearing calls for much proactive behavior on the part of the family, and we urge health professionals to advise in appropriate ways (which are discussed in Kushalnagar et al., 2010b, but which we outline in the next two sections). It is the responsibility of health professionals to do this because health professionals are the ones who families most often turn to first, given that they are the ones who usually deliver the diagnosis of hearing loss. And it is the responsibility of health professionals to do this particularly well and with utter thoroughness, since families receiving the information that their newborn or young child is deaf are in a vulnerable state, often of grief (Kurtzer-White \& Luterman, 2003). Their lack of information about and familiarity with deafness can mean they initially suffer, and in this way, they have much in common with people experiencing illness. Hall \& Schneider (2008) point out that sick people are more vulnerable for a variety of reasons beyond the fact that they are in pain, including the facts that they feel disabled and defeated by the illness; they are exhausted due to dealing with the illness; their control over their bodies (or, in the case of parents, over their child's body) is eroded; they are baffled by the condition and wonder about its origin, its trajectory, the uncertainty of everything; they are terrified of what they do not understand; they are isolated from others because they are suddenly different. Add it all up and the power of health professionals dealing with these families is huge; hence, their responsibility to give accurate and appropriate information and advice is likewise huge. True, the law gives families the right to make decisions about whether, when, and how to manage the physical and social needs of their child in most instances, and this applies to the language needs of deaf children (Ouelette, 2011), but the families rely heavily on consultation with their health professionals. 


\subsection{The ideal situation}

In the ideal situation deaf children will be raised with sign language, regardless of their speech-producing and speech-processing skills, so that they will be bilingual in the bimodal sense (i.e. in both a sign language and a written language). All will have fluency and high literacy in both a sign language and a written language, and those who gain good speech skills will be bilingual and highly literate in both a sign language and a spoken/written language. Bilingualism is an added enormous benefit, since it has many cognitive advantages for everyone, including deaf people (Kushalnagar et al., 2010a). In developed countries (and in many underdeveloped countries), we have embraced the idea that our children should know more than one language. More and more elementary schools offer a second language, most middle schools do, and both high schools and colleges have foreign language requirements. Further, it has become popular in many countries to teach hearing babies some sign language, to further their expressive abilities. Given all this, it is difficult to understand how anyone could advise against offering deaf children sign language.

Health professionals can help to achieve this ideal situation by properly advising the families of deaf children about the biological nature of first language acquisition and by urging them to consult with experts in deaf matters (NAD, 2000). There are several recommendations they should make. First, the family of the deaf child needs to learn sign language; a deaf child whose hearing parents and siblings, particularly hearing mothers, sign with them demonstrate language expressiveness and theory of mind on a par with hearing children of the same age. (Schick et al. 2007; Spencer, 1993). But family is not enough. The deaf child needs to be brought into contact with a community of deaf signers so as to be exposed to good models of signing on a regular and frequent basis. The family should be in contact with signing community support groups in order to stay informed and be active in deaf issues and events: deaf advocacy groups, local deaf and hard of hearing community centers, and local and/or state deaf services bureaus. The family must advocate for their child's needs at school, including asking for an interpreter when necessary and whatever special aids or considerations are appropriate with respect to the instruction being given. And most of all, the family needs to affiliate and be active with parents of deaf children support groups, playgroups, and otherwise form friendships and provide visitation for themselves and their deaf child with other deaf parents and children. All of these activities have been reported to contribute to positive quality of life for deaf children.

Parents need to involve themselves in ways that help them develop clearer understanding of their deaf child. One of the greatest dangers to the emotional development of a young deaf child occurs when the parents (or one of them) do not understand the child's situation properly or project fear, concern, or other kinds of emotional distress into their relationship with the child or even into the larger environment of their child (Leigh, 2009; Marschark, 1997, 2009). Parents should be alerted to and helped to avoid the negativity of the "hearing impaired" discourse so rife among medical professionals and special educators. They should be encouraged to develop strong relationships with deaf people themselves as soon as possible and to get involved with the rich social and cultural lives of this community.

The advent of a deaf child into a family is a gateway to a new language and a rich culture. Families need to become informed, and there are good works out there to help, like Bauman (2008); Bauman \& Murray (2009); Lane et al. (1996); Marschark (2009); Marschark et al. (2010a, 2010b); and Padden \& Humphries (2005), all of which give substantial references. 


\subsection{The less than ideal situation}

While what we have described in the last section is the ideal situation that a family should strive for, practical factors may inhibit achieving such a situation. In particular, the family of a deaf child may not have easy access to a signing community or perhaps even to an isolated signer. Rural families, in particular, may feel betrayed by advice to learn sign language. A family in this situation has little choice but to become more active in their child's proper development. There are a number of strategies that the family can adopt to maximize the potential for the child to acquire a first language, and there are websites to help (Enabling Education Network, n.d.).

First, the family must try to learn a sign language in the best way possible. It may require some driving time, but sign language classes are increasingly more popular and widespread. There are literally thousands of schools, colleges, or community centers offering courses today in many developed countries. And if the local community is small, the family can enlist the whole community in the effort to learn a sign language and to communicate with the deaf child in that sign language. Spiritual leaders (ministers, rabbis, etc.) can play a guiding role here, helping the community to understand both what it has to offer the deaf child and what the deaf child has to offer the community (Blankmeyer-Burke et al., 2011). A community might want to advertise for and hire a sign language teacher to come stay in their community for a prolonged period of time, teaching everyone who is willing to learn. There are also multiple online sites and DVDs to help someone learn a sign language (see the website of DawnSignPress in the United States or ForestBooks in the United Kingdom, for example).

Second, the family should find out about camps for deaf children, where their child can play with other deaf children and interact with adults who use a sign language as their most comfortable language (or among their most comfortable languages) and identify themselves as Deaf (that is, part of Deaf culture) or as very knowledgeable of Deaf culture (in the USA: Laurent Clerc National Deaf Education Center, n.d.). Many such camps exist: in the United States they are scattered across the states; in Germany the German Deaf Youth Association annually organizes camps for Deaf children and Deaf Youth. Some have scholarships available. Some are for the entire family (in the USA: Raising Deaf Kids, n.d.; in Canada: Deaf Children's Society of BC, n.d.; in Germany: Bundeselternverband gehörloser Kinder e.V., n.d.).

Third, the family must be resourceful. The family could start a sign language class with parents and children who are not deaf. Many hearing families are now encouraged about their hearing children learning to sign and communicating with them. If a parent can manage to learn enough sign language to get ahead of the others in the class, that parent can lead the class, along with the deaf child. Having others sign to the deaf child is important. If the family has relatives in a city with a thriving Deaf community arranging to spend time there, as hard as it may be on the family, may be the sacrifice that makes the world of difference to the child's development. The family might want to get online (using current video technology: Skype, iChat, gChat, ooVoo, etc.) with someone who knows many people in the Deaf community (perhaps a professor at a Deaf Studies program at some university or someone who works in a Deaf and Hearing Community Center in some urban area) and see if a Deaf family might like to come visit them for an extended period. The deaf child in one's home makes the home eligible to obtain a videophone setup from a video relay service or 
from welfare agencies. With this setup, the family can call directly via video to deaf people who they meet and form a stronger relationship. Sign language tutoring via VP (videophone) might even be arranged. Just social chatting via video with deaf people, other parents, advisors, etc. can help greatly. When the deaf child is old enough, he/she can use the videophone as well. This is a normal aspect of life among deaf people now and needs to be the same for the deaf child in any home as well as for the parents of that child.

If the family has opportunities to live in an urban area which has a Deaf community, now might be the time to realize those opportunities. While this may feel drastic, it was not too long ago that families with deaf children often moved to where there were schools for the deaf, so that their children could receive an education (Sacks, 1989).

\subsection{The close-to-untenable situation}

Another serious impediment to the ideal situation is posed by socioeconomic factors which are often unalterable. A family may not have the educational background to take on such proactive behavior or may not have the financial resources to do so; the family may not have the education or technological literacy needed to access and use the information available on sign language, and online access and webcam may not be available. Further, a family's home language may complicate the situation in ways that make the suggestions above infeasible (such as a Hmong family in Minnesota). Likewise, limited educational achievement may limit a family's ability to overcome cultural biases and learn another language, particularly one in a different modality. These are huge challenges, but if health professionals take a strong guiding role, they may not be insurmountable. People in these situations are already marginalized. If we allow the infeasibility of providing access to a sign language to stop us from making efforts in these situations, those children who do not find accessible language via an implant will be marginalized much further. The efforts might have to be extraordinary, but the damage risked by not making these efforts is also extraordinary.

\subsection{The role of health professionals in achieving the ideal situation}

A recent study by the United States Government Accountability Office (2011) concludes that parents of deaf children are ill-advised when it comes to matters of language and educational options. Families need to understand the crucial importance of first language acquisition for their children so that they can, in fact, be as resourceful as possible. And health professionals must help them understand. Both health professionals and families need to be very careful not to give in to low expectations as far as language and cognitive development are concerned. Deaf people, both as individuals, and as a social group, have been severely damaged by a history of expecting language delay and cognitive delay (Gregory, 1995; Gregory et al., 1995). This ideology of low expectation is unacceptable. There is no reason for it. With a signing environment and rich social world for the child, delayed development will not happen. Without sign language, there is a significant risk that it will. Equally important, however, is the fact that rosy scenarios of hopefulness from health professionals who ignore clear indications of language and cognitive development delay are not acceptable either. Parents need to know, via appropriate and whole-child assessment, if their child is developing well. Assessment focused exclusively on speech and auditory development, for example, is inadequate to measure overall language and cognitive development and cannot be equated with it. 


\section{The future}

Presently many deaf implanted children do not feel at ease communicating in a hearing environment, and many do not succeed at it to the point where they can converse comfortably with strangers or even in a group of same-age peers. Further, a significant number simply do not thrive linguistically in a strictly aural/oral environment. We cannot look exclusively at the successful implanted children, who typically have a family that is economically and educationally able to provide them support in their rehabilitation and who have reliable ongoing rehabilitation. Many children are not in that situation, and even some who are in that situation do not experience success with respect to solid first language acquisition. We also cannot count on improvements in CI technology to ameliorate the social situation, language delay or the cognitive risk. What we need right now is studies of the most successful CI users. We need to understand what makes them stars that go beyond basic speech recognition and production. We must find out whether matters that we can easily control are most pertinent, such as surgical technique (Meshik et al., 2010). In the same vein, we must determine whether some methods of "rehabilitation" yield much better results than others. Then we must figure out whether some other factors are the keys. It is imperative to find out whether there are, in fact, predictable correlates to success and, if feasible, strive to ensure those correlates for all implanted children.

We need also to devise new protocols for young children with implants and evaluate them. For example, a protocol that calls for the parents and child to begin using a sign language from birth or as soon as possible after hearing-loss is detected, and well before the surgery, and continuing to use that sign language after the surgery, is supported by the research we have now. Such a protocol or other similar protocols is critically important for all implanted children, and it is the most conservative approach to protect the right to language for those children who receive little to no language input from the implant. We need a protocol that includes robust and frequent authentic assessments of the child's development (authentic in that it assesses language (not simply speech), communication, and literacy development) and monitors this development through a running record over time.

\section{Conclusion}

In order to ensure the typical cognitive development milestones, and hence the psychosocial health, of deaf children, we must make sure they acquire a first language. Since a sign language is the only type of language guaranteed to be accessible to deaf children, we must make sure they acquire a sign language. With a sign language, a deaf child who is implanted has the best chance at being cognitively healthy and of becoming bimodallybilingual. It is well-recognized that bilingualism is positive for all people, children included. Around the world, educational systems require study of a second language before a child can graduate at the secondary level. Bilingualism can only be beneficial to the deaf child, as well. The acquisition of sign language provides a medical safety net for all deaf children. We simply cannot wait to see who does not thrive with an implant before offering sign language; for the child who does not thrive, the best result of such waiting is language delay, itself quite problematic, and the worst result is linguistic deprivation, a calamity.

It is the responsibility and obligation of health professionals to guide families of deaf newborns and newly deafened children toward choosing to raise their child with a sign 
language. If that is done, the harm that we presently see in some implanted deaf children who are raised without sign language experience will become a regret of the past.

\section{References}

Barnes, J. (1994). Pediatric Cochlear Implants: An Overview of the Alternatives in Education and Rehabilitation, Alexander Graham Bell Association for the Deaf, ISBN 9780882002040, Washington, DC

Bauman, H-D. (Ed.). (2008). Open Your Eyes: Deaf Studies Talking, University of Minnesota Press, ISBN 978-0816646180, Minneapolis, MN

Bauman, H-D. \& Murray, J. (2009). Reframing: From Hearing Loss to Deaf-gain. Deaf Studies Digital Journal, Vol.1, No.1. Retrieved from: http://dsdj.gallaudet.edu/

Bilger, R. (1977). Evaluation of Subjects Presently Fitted with Implanted Auditory Prostheses. Annals of Otology, Rhinology, and Larygology, Vol. 86, pp. 1-176

Blankmeyer-Burke, T.; Kushalnagar, P.; Mathur, G.; Napoli, D-J.; Rathmann, C. \& VanGilder, K. (2011). The Language Needs of Deaf and Hard-of-hearing Infants and Children: Information for Spiritual Leaders and Communities. Journal of Religion, Disability and Health, Vol.15, pp. 272-295, ISSN 1522-8967

Blume, S. (2009). The Artificial Ear: Cochlear Implants and The Culture of Deafness, Rutgers University Press, ISBN 978-0813546605, Camden, NJ

Bouchard, M-E.; Ouellet, C. \& Cohen, H. (2008). Speech Development in Prelingually Deaf Children with Cochlear Implants. Language and Linguistics Compass, Vol.2, pp. 1-18

Borkowski, G.; Hildmann, H. \& Stark (2002). Surgical Aspects of Cochlear Implantation in Young and Very Young Children, In: Cochlear Implants: An Update, T. Kubo; Y. Takahashi; \& T. Iwaki, pp. 223-226, Kugler Publications, ISBN 978-9062991914, The Hague, The Netherlands

Brackmann, D.; Shelton, C. \& Arriaga, M. (2001). Otologic Surgery, (2nd edition), Saunders, ISBN 978-0721689760, Philadelphia, PA

Brentari, D. (Ed.). (2010). Sign Languages, Cambridge University Press, ISBN 978-0521883702, Cambridge, UK

Bundeselternverband gehörloser Kinder e.V. (n.d.). 18.07.11, Available from http://www.gehoerlosekinder.de/

Chamberlain, C. \& Mayberry, R. (2008). American Sign Language Syntactic and Narrative Comprehension in Skilled and Less Skilled Readers: Bilingual and Bimodal Evidence for the Linguistic Basis of Reading. Applied Psycholinguistics, Vol.29, No.3, pp. 367-388, ISSN: 0142-7164

Chamberlain, C.; Morford, J. \& Mayberry, R. (Eds.). (2000). Language Acquisition by Eye, Lawrence Erlbaum Associates, ISBN 978-0805829372, Mahwah, NJ

Christensen, J. \& Leigh, I. (2002). Cochlear Implants in Children: Ethics and Choices, Gallaudet University Press, ISBN 978-1563681165, Washington, DC

Cohen, N. \& Roland, J. (2006). Complications of Cochlear Implant Surgery, In: Cochlear Implants, (2nd edition), S. Waltzman \& T. Roland, (Eds.), pp. 205-213, Thieme Medical Publishers, ISBN 978-1588904133, New York, NY

Curtiss, S. (1977). Genie: A Psycholinguistic Study of a Modern-day "Wild Child", Academic Press, ISBN 978-0121963507, New York, NY 
Curtiss, S. (1994). Language as a Cognitive System: Its Independence and Selective Vulnerability, In: Noam Chomsky: Critical Assessments: 4, C. Otero, (Ed.), pp. 211-255, Routledge, ISBN 978-0415010054, London, UK

Davis, D. (1997). Cochlear Implants and the Claims of Culture? A Response to Lane and Grodin. Kennedy Institute of Ethics Journal, Vol.7, No.3, pp. 253-258, ISSN 1054-6863

Deaf Children's Society of BC. (n.d.). Learning Vacation Experience, 18.07.11, Available from http://www.deafchildren.bc.ca/about-us/history

Djourno, A.; Eyries, C. \& Vallancien, B. (1957). De L'excitation Electrique du Nerf Cochleaire Chez L'homme, Par Induction a Distance, a L'aide D'un Micro-bobinage Inclus à Memeure. La Presse Médicale, Vol.65, No.63, pp. 31 (cited in Eisen, 2000)

Dockrell, J., \& Messer, D. (1999). Children's Language and Communication Difficulties: Understanding, Identification, and Intervention, Cassell, ISBN 978-0304336579, New York, NY

Emmorey, K. (2001). Language, Cognition and the Brain: Insights from Sign Language Research, Lawrence Erlbaum Associates, ISBN 978-0805833980, Mahwah, NJ

Eisen, M. (2000). The History of Cochlear Implants, In: Cochlear Implants: Principles and Practices, J. Niparko, (Ed.), pp. 89-93, Lippincott Williams \& Wilkins, ISBN 9780781717823, Philadelphia, PA

Enabling Education Network. (n.d.). Services for Deaf People in a Rural Setting: Issues and Recommendations for Sign Language, 18.07.11, Available from

http://www.eenet.org.uk/resources/docs/signlang.php

Estabrooks, W. (2006). Auditory-verbal Therapy and Practice, Alexander Graham Bell Association for the Deaf, ISBN 978-0882002231, Washington, DC

Federal Drug Administration. (2011). Benefits and Risks of Cochlear Implants, 18.07.11, Available from http://www.fda.gov/MedicalDevices/ProductsandMedical Procedures/ImplantsandProsthetics/CochlearImplants/ucm062843.htm

Feinberg, J. (2007). The Child's Right to an Open Future, In: Philosophy of Education: An Anthology, R. Curren, (Ed.), pp. 112-123, Wiley-Blackwell, ISBN 978-1405130226, Malden, MA

Fink, N.; Wang, N-Y.; Visaya, J.; Niparko, J.; Quittner, A. \& Eisenberg, L. (2007). Childhood Development after Cochlear Implantation Study: Design and Baseline Characteristics. Cochlear Implants International, Vol.8, No.2, pp. 92-116, ISSN 14670100

Fischer, S. (1998). Critical Periods for Language Acquisition: Consequences for Deaf Education, In: Issues Unresolved: New Perspectives on Language and Deaf Education, A. Weisel, (Ed.), pp. 9-26, Gallaudet University Press, ISBN 978-1563680670, Washington, DC

Gao, T. (2007). A Neglected Culture: How Cochlear Implants Affect Deaf Children's SelfEsteem, In: DIAGLOGUES@RU, 18.07.11, Available from

http://dialogues.rutgers.edu/vol_06/essays/documents/gao.pdf

Gregory, S. (1995). Deaf Children and Their Families, Cambridge University Press, ISBN 9780521438476, Cambridge, UK

Gregory, S.; Bishop, J. \& Sheldon, L. (1995). Deaf Young People and Their Families, Cambridge University Press, ISBN 978-0521429986, Cambridge, UK

Grimshaw, G.; Adelstein, A.; Bryden, M. \& MacKinnon, G. (1998). First-language Acquisition in Adolescence: Evidence for a Critical Period for Verbal Language Development. Brain and Language, Vol.63, No.2, pp. 237-255, ISSN 0093-934X 
Gulya, A.; Minor, L. \& Poe, D. (2010). Glasscock-Shambaugh's Surgery of the Ear, (6th edition), People's Medical Publishing House USA, ISBN 978-1607950264, Shelton, CT

Hall, M. \& Schneider, C. (2008). Patients as Consumers: Courts, Contracts, and the New Medical Marketplace. Michigan Law Review, Vol.106, pp. 643-689

Hintermair, M. (2000). Hearing Impairment, Social Networks, and Coping: The Need for Families with Hearing-Impaired Children to Relate to Other Parents and to Hearing-Impaired Adults. American Annals of the Deaf, Vol.145, pp. 41-53, ISSN 0002-726X

Hoffmeister, R. (2000). A Piece of the Puzzle: The Relationship between ASL and English Literacy in Deaf Children, In: Language Acquisition by Eye, C. Chamberlain; J. Morford, \& R. Mayberry, (Eds.), pp. 143-163, Lawrence Erlbaum Associates, ISBN 978-0805829372, Mahwah, NJ

Holte, M. \& Dinis, M. (2001). Self-esteem Enhancement in Deaf and Hearing Women: Success Stories. American Annals of the Deaf, Vol.146, No.4, pp. 348-354, ISSN 0002726X

House, W. (1991). Cochlear Implants and Children. The Western Journal of Medicine, Vol.154, No.6, pp. 717-718

Institute of Medicine. (2011). Medical Devices and the Public's Health: The FDA 510(k) Clearance Process at 35 years, National Academies Press, ISBN 978-0309212427, Washington, $\mathrm{DC}$

Johnston, T. (2006). Response to Comments. Sign Language Studies, Vol.6, No.2, pp. 225-243, ISSN 0302-1475

Kisor, H. (1990). What's That Pig Outdoors?: A Memoir of Deafness, Hill and Wang, ISBN 9780809096893, New York, NY

Krausneker, V. (2008). The Protection and Promotion of Sign Languages and the Rights of Their Users in Council of Europe Member States: Needs Analysis, In: Council of Europe - Partial Agreement in the Social and Public Health Field, 15.07, 11, Available from http://www.coe.int/t/DG3/Disability/Source/Report_Sign_languages_ final.pdf

Kurtzer-White, E. \& Luterman, D. (2003). Families and Children with Hearing Loss: Grief and Coping. Mental Retardation and Developmental Disabilities Research Reviews, Vol.9, No.4, pp. 232-235, ISSN 1940-5529

Kushalnagar, P.; Krull, K.; Hannay, H.; Mehta, P.; Caudle, S. \& Oghalai, J. (2007). Intelligence, Parental Depression and Behavior Adaptability in Deaf Children Being Considered for Cochlear Implantation. Journal of Deaf Studies and Deaf Education, Vol.12, No.3, pp. 335-349, ISSN 1081-4159

Kushalnagar, P.; Hannay, H. \& Hernandez, A. (2010a). Bilingualism and Attention: A Study of Balanced and Unbalanced Bilingual Deaf Users of American Sign Language and English. Journal of Deaf Studies and Deaf Education, Vol.15, No.3, pp. 263-273, ISSN 1081-4159

Kushalnagar, P.; Mathur, G.; Moreland, C.; Napoli, D-J.; Osterling, W.; Padden, C. \& Rathmann, C. (2010b). Infants and Children with Hearing Loss Need Early Language Access. Journal of Clinical Ethics, Vol.21, No.2, pp. 143-154, ISSN 1046-7890

Kushalnagar, P.; Topolski, T.; Schick, B.; Edwards, T.; Skalicky, A. \& Patrick, D. (2011). Mode of Communication, Perceived Level of Understanding, and Perceived Quality of Life in Youth Who are Deaf or Hard of Hearing. Journal of Deaf Studies and Deaf Education, Vol.16, No.4, pp. 512-523, ISSN 1081-4159 
Lane, H. (2005). Ethnicity, ethics, and the Deaf-World. Journal of Deaf Studies and Deaf Education, Vol.10, No.3, pp. 291-310, ISSN 1081-4159

Lane, H. \& Grodin, M. (1997). Ethical Issues in Cochlear Implant Surgery: An Exploration into Disease, Disability, and the Best Interests of the Child. Kennedy Institute of Ethics Journal, Vol.7, No.3, pp. 231-251, ISSN 1054-6863

Lane, H.; Hoffmeister, R. \& Bahan, B. (1996). A Journey into the Deaf-World, Dawn Sign Press, ISBN 978-0915035632, San Diego, CA

Laurent Clerc National Deaf Education Center. (n.d.) Summer Camps for Deaf and Hard of Hearing Children and Teens, 18.07.11, Available from http://www.gallaudet.edu/ x17375.xml

Lederberg, A. \& Goldbach, T. (2002). Parental Stress and Social Support in Hearing Parents: Pragmatic and Dialogic Characteristics. Journal of Deaf Studies and Deaf Education, Vol.7, No.4, pp. 330-345, ISSN 1081-4159

Leigh, I. W. (2009). A Lens on Deaf Identities, Oxford University Press, ISBN 978-0195320664, Oxford, UK

Lenneberg, E. (1967). Biological Foundations of Language, John Wiley \& Sons, ISBN 9780471526261, New York, NY

Lower, Gavin. (2011). Cochlear Recalls Implants: Top manufacturer's action affects latest range of devices after rise in failures. The Wall Street Journal, Corporate News Section B 5, Tuesday, September 13, 2011.

MacSweeney, M. (1998). Cognition and Deafness, In: Issues in Deaf Education, S. Gregory, P. Knight, W. MacCracken, S. Powers \& L. Watson, (Eds.), pp. 20-27, David Fulton Publishers, ISBN 978-1853465123, London, UK

Marschark, M. (1997). Psychological Development of Deaf Children, Oxford University Press, ISBN 978-0195115758, Oxford, UK

Marschark, M. (2009). Raising and Educating a Deaf Child: A Comprehensive Guide to the Choices, Controversies, and Decisions Faced by Parents and Educators, Oxford University Press, ISBN 978-0195376159, Oxford, UK

Marschark, M.; Rhoten, C. \& Fabich, M. (2007). Effects of Cochlear Implants on Children's Reading and Academic Achievement. Journal of Deaf Studies and Deaf Education, Vol.12, No.3, pp. 269-282, ISSN 1081-4159

Marschark, M. \& Spencer, P. (Eds.) (2010a). The Oxford Handbook of Deaf Studies, Language, and Education, Vol.1, (2nd edition), Oxford University Press, ISBN 978-0199750986, Oxford, UK

Marschark, M. \& Spencer, P. (Eds.) (2010b). The Oxford Handbook of Deaf Studies, Language, and Education, Vol.2, Oxford University Press, ISBN 978-0195390032, Oxford, UK

Mathur, G. \& Napoli, D-J. (Eds.). (2010). Deaf Around the World: The Impact of Language, Oxford University Press, ISBN 978-0199732531, Oxford, UK

Mayberry, R. \& Eichen, E. (1991). The Long-lasting Advantage of Learning Sign Language in Childhood: Another Look at the Critical Period for Language Acquisition. Journal of Memory and Language, Vol.30, No.4, pp. 486-512, 0749-596X

McGuinness, D. (2005). Language Development and Learning to Read: The Scientific Study of How Language Development Affects Reading Skill, MIT Press, ISBN 978-0262633406, Cambridge, MA

Meadow-Orlans, K. (1994). Stress, Social Support, and Deafness: Perceptions of Infants' Mothers and Fathers. Journal of Early Intervention, Vol.18, No.1, pp. 91-102, ISSN 1053-8151 
Meier, R. \& Newport, E. (1990). Out of the Hands of Babes: On a Possible Sign Advantage. Language, Vol.66, No.1, pp. 1-23

Meisel, J. (2011). First and Second Language Acquisition: Parallels and Differences, Cambridge University Press, ISBN 978-0521557641, Cambridge, UK

Meshik, X.; Holden, T.; Chole, R. \& Hullar, T. (2010). Optimal Cochlear Implant Insertion Vectors. Otology and Neurotology, Vol.31, No.1, pp. 58-63, ISSN 1531-7129

Mogford, K. (1993). Oral Language Acquisition in the Prelingually Deaf, In: Language Development in Exceptional Circumstances, D. Bishop \& K. Mogford, (Eds.), pp. 110131, Lawrence Erlbaum Associates, ISBN 978-0863773082, Hillsdale, NJ

Morgan, G. \& Woll, B. (Eds.). (2002). Directions in Sign Language Acquisition, John Benjamins, ISBN 978-1588112354, Amsterdam, The Netherlands

National Association of the Deaf. (2000). NAD Position Statement on Cochlear Implants, 18.07.11, Available from http://www.nad.org/issues/technology/assistive listening/cochlear-implants

Neville, H. (1995). Developmental Specificity in Neurocognitive Development in Humans, In: The Cognitive Neurosciences, M. Gazzaniga, (Ed.), pp. 219-231, MIT Press, ISBN 978-0262071574, Cambridge, MA

Newport, E. (1990). Maturational Constraints on Language Learning. Cognitive Science, Vol. 14, No.1, pp. 11-28

O'Reilly, R.; Mangiardi, A. \& Bunnell, T. (2008). Cochlear Implants, In: Access: Multiple Avenues for Deaf People, D. DeLuca, I. Leigh, K. Lindgren, \& D-J. Napoli, (Eds.), pp. 38-74, Gallaudet University Press, ISBN 978-1563683930, Washington, DC

Ouellette, A. (2011). Hearing the Deaf: Cochlear Implants, the Deaf Community, and Bioethical Analysis. Valparaiso University Law Review, Vol.45, No.3, pp. 1247-1270

Padden, C. \& Humphries, T. (2005). Inside Deaf Culture, Harvard University Press, ISBN 978-0674015067, Cambridge, MA

Pakaluk, E. \& Neville, H. (2010). Biological Bases of Language Development. In: Encyclopedia of Early Childhood Development, R. Tremblay, R. Peters, M. Boivin \& R. Barr, (Eds.), pp. 1-7, Center of Excellence for Early Child Development, Retrieved from http://www.child-encyclopedia.com/documents/Pakulak-NevilleANGxp.pdf

Peterson, N.; Pisoni, D. \& Miyamoto, R. (2010). Cochlear Implants and Spoken Language Processing Abilities: Review and Assessment of the Literature. Restorative Neurology and Neuroscience, Vol.28, No.2, pp. 237-250, ISSN 0922-6028

Petitto, L. \& Marentette, P. (1991). Babbling in the Manual Mode: Evidence for the Ontogeny of Language. Science, Vol.251, No.5000, pp. 1493-1496, ISSN 0036-8075

Plaza Pust, C. \& Morales López, E. (2008). Sign Bilingualism: Language Development, Interaction, and Maintenance in Sign Language Contact Situations, John Benjamins, ISBN 978-9027241498, Amsterdam, The Netherlands

Poizner, H.; Klima, E. \& Bellugi, U. (1987). What the Hands Reveal about the Brain, MIT Press, ISBN 978-0262161053, Cambridge, MA

Punch, R. \& Hyde, M. (2011). Social Participation of Children and Adolescents With Cochlear Implants: A Qualitative Analysis of Parent, Teacher, and Child Interviews. Journal of Deaf Studies and Deaf Education, Vol.16, No.4, pp. 474-493, ISSN 1081-4159

Raising Deaf Kids. (n.d.). Summer camps, 18.07.11, Available from http://www.raisingdeafkids.org/growingup/camp.php 
Ramsey, C. (2000). Ethics and Culture in the Deaf Community Response to Cochlear Implants. Seminars in Hearing, Vol.21, No.1, pp. 75-86, ISSN 0734-0451

Restuccia, A. (2010). Michael Schwartz: Multiple Communication Methods Assist Deaf Law Professor In and Outside of the Classroom, In The Daily Orange: The Independent Student Newspaper of Syracuse, New York, 07.03.11, Available from http://www.dailyorange.com/2.8691/michaelschwartz-multiple-communicationmethods-assist-deaf-law-professor-in-and-outside-ofthe-classroom-1.1237578

Rhoades, E. (2006). Research Outcomes of Auditory-Verbal Intervention: Is the Approach Justified? Deafness and Education International, Vol.8, No.3, pp. 125-143, ISSN 1464-3154

Ronnberg, J. (2010). Working Memory, Neuroscience, and Language: Evidence from Deaf and Hard-of-hearing Individuals, In: The Oxford Handbook of Deaf Studies, Language, and Education, Vol.1, (2nd edition), M. Marschark \& P. Spencer, (Eds.), pp. 478-490, Oxford University Press, ISBN 978-0199750986, Oxford, UK

Sacks, O. (1989). Seeing Voices: A Journey into the World of the Deaf, University of California Press, ISBN 978-0520060838, Berkeley, CA

Santarelli, R.; De Filippi, R.; Genovese, E. \& Arslan, E. (2008). Cochlear Implantation Outcome in Prelingually Deafened Young Adults. Audiology and Neurotology, Vol.13, No.4, pp. 257-265, ISSN 1420-3030

Schick, B.; Marschark, M. \& Spencer, P. (Eds.). (2006). Advances in the Sign Language Development of Deaf Children, Oxford University Press, ISBN 978-0195180947, New York, NY

Schick, B.; de Villiers, P.; de Villiers, J. \& Hoffmeister, R. (2007). Language and Theory of Mind: A Study of Deaf Children. Child Development, Vol.78, No.2, pp. 376-396, ISSN 0009-3920

Shannon, R.; Fu, Q-J.; Galvin, J. \&. Friesen, L. (2010). Speech Perception with Cochlear Implants, In: Cochlear Implants: Auditory Prostheses and Electrical Hearing, F-G. Zeng, A. Popper \& R. Fay, (Eds.), pp. 334-376, Springer, ISBN 978-0387225852, New York, NY

Shattuck, R. (1980). The Forbidden Experiment: The Story of the Wild Boy of Aveyron, Farrar, Straus and Giroux, ISBN 978-0436458750, New York, NY

Simmons, F. (1966). Electrical Stimulation of the Auditory Nerve in Man. Archives of Otolaryngology, Vol.84, No.1, pp. 2-54 (cited in Eisen, 2000)

Snoddon, K. (2005). Return, In: Between Myself and Them: Stories of Disability and Difference, C. Krause, (Ed.), pp. 179-188, Second Story Press, ISBN 978-1896764993, Toronto, Canada

Snow, J. \& Wackym, P. (2008). Ballenger's Otorhinolaryngology, (17th edition), People's Medical Publishing House, ISBN 978-1550093377, Shelton, CT

Spencer, P. (1993). The Expressive Communication of Hearing Mothers and Deaf Infants. American Annals of the Deaf, Vol.138, No.3, pp. 275-283, ISSN 0002-726X

Steenerson, R.; Cronin, G. \& Gary, L. (2001). Vertigo after Cochlear Implantation. Otology and Neurotology, Vol.22, No.6, pp. 842-843, ISSN 1531-7129

Stemmer, B. \& Whitaker, H. (Eds.) (2008). Handbook of the Neuroscience of Language, Academic Press, ISBN 978-0080453521, London, UK

Strong, M. \& Prinz, P. (2000). Is American Sign Language Skill Related to English Literacy? In: Language acquisition by eye, C. Chamberlain, J. Morford \& R. Mayberry, (Eds.), pp. 131-142, Lawrence Erlbaum Associates, ISBN 978-0805829372, Mahwah, NJ 
Sutton-Spence, R. \& Napoli, D-J. (2009). Humour in Sign Languages: The Linguistic Underpinnings, Centre for Deaf Studies, Trinity College, ISSN: 2009-1680, Dublin, Ireland

Szagun, G. (2008). The Younger the Better? Variability in Language Development of Young German-speaking Children with Cochlear Implants, In: Proceedings of the Child Language Seminar 2007 - 30th Anniversary, T. Marinis, A. Papangeli \& V. Stojanovik, (Eds.), pp. 183-194, University of Reading Press, Reading, UK

Turner, C.; Reiss, L. \& Gantz, B. (2007). Combined Acoustic and Electric Hearing: Preserving Residual Acoustic Hearing. Hearing Research, 42, pp. 164-171

Tyler, R.; Witt, S.; Dunn, C.; Perreau, A.; Parkinson, A. \& Wilson, B. (2010). An Attempt to Improve Bilateral Cochlear Implants by Increasing the Distance Between Electrodes and Providing Complementary Information to the Two Ears. Journal of the American Academy of Audiology, Vol.21, No.1, pp. 52-65

United States Government Accountability Office. (2011). Deaf and Hard-of-hearing Children: Federal Support for Developing Language and Literacy, 18.07.11, Available from http://www.gao.gov/products/GAO-11-357

Valente, J. (2011). Cyborgization: Deaf Education for Young Children in the Cochlear Implantation Era. Qualitative Inquiry, Vol.17, No.7, pp. 639-652, ISSN 1077-8004

Walker, G. (2008). A Conversation with Grace Walker: Personal Experiences with a Cochlear Implant, In: Access: Multiple Avenues for Deaf People, D. DeLuca, I. Leigh, K. Lindgren, \& D-J. Napoli, (Eds.), pp. 140-145, Gallaudet University Press, ISBN 9781563683930, Washington, DC

Waltzman, S. \& Roland, T. (2005). Cochlear Implantation in Children Younger Than 12 Months. Pediatrics, Vol.116, No.4, pp. e487-e493, ISSN 0031-4005

Watson, L. \& Gregory, S. (2005). Non-use of Implants in Children: Child and Parent Perspectives. Deafness and Education International, Vol.7, No.1, pp. 43-58, ISSN 1464-3154

Wilbur, R. (2008). How to Prevent Educational Failure, In: Signs and Voices: Deaf Culture, Identity, Language and Arts, K. Lindgren, D. DeLuca \& D-J. Napoli, (Eds.), pp. 117138, Gallaudet University Press, ISBN 978-1563683633, Washington, DC

Wilson, B.; Finley, C.; Lawson, D.; Wolford, R.; Eddington, D. \& Rabinowitz, W. (1991). Better Speech Recognition with Cochlear Implants. Nature, Vol.352, No.6332, pp. 236-238 (cited in Eisen, 2000)

Yoshinaga-Itano, C.; Sedey, A.; Coulter, D. \& Mehl, A. (1998). Language of Early- and LaterIdentified Children with Hearing Loss. Pediatrics, Vol.102, No.5, pp. $1161-1171$, ISSN 0031-4005

Yoshinaga-Itano, C.; Coulter, D. \& Thomson, V. (2000). The Colorado Hearing Screening Program: Effects on Speech and Language for Children with Hearing Loss. Journal of Perinatology, Vol.20, No.8s, pp. s132 -s142, ISSN 0743-8346

Young, C. (2002). Sound Judgement: Does Curing Deafness Really Mean Cultural Genocide? In: The CBS Interactive Business Network, 18.07.11, Available from http://findarticles.com/p/articles/mi_m1568/is_11_33/ai_84246679/

Zimmerman, A. (2009). Do You Hear the People Sing? Balancing Parental Authority and a Child's Right to Thrive: The Cochlear Implant Debate. Journal of Health and Biomedical Law, Vol.5, No.2, p. 309 


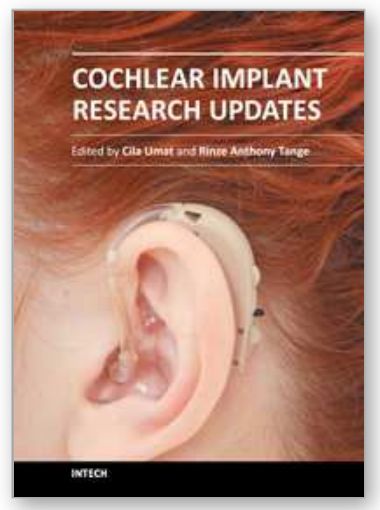

\author{
Cochlear Implant Research Updates \\ Edited by Dr. Cila Umat
}

ISBN 978-953-51-0582-4

Hard cover, 232 pages

Publisher InTech

Published online 27, April, 2012

Published in print edition April, 2012

For many years or decades, cochlear implants have been an exciting research area covering multiple disciplines which include surgery, engineering, audiology, speech language pathology, education and psychology, among others. Through these research studies, we have started to learn or have better understanding on various aspects of cochlear implant surgery and what follows after the surgery, the implant technology and other related aspects of cochlear implantation. Some are much better than the others but nevertheless, many are yet to be learnt. This book is intended to fill up some gaps in cochlear implant research studies. The compilation of the studies cover a fairly wide range of topics including surgical issues, some basic auditory research, and work to improve the speech or sound processing strategies, some ethical issues in language development and cochlear implantation in cases with auditory neuropathy spectrum disorder. The book is meant for postgraduate students, researchers and clinicians in the field to get some updates in their respective areas.

\title{
How to reference
}

In order to correctly reference this scholarly work, feel free to copy and paste the following:

Tom Humphries, Poorna Kushalnagar, Gaurav Mathur, Donna Jo Napoli, Carol Padden, Christian Rathmann and Scott Smith (2012). Cochlear Implants and the Right to Language: Ethical Considerations, the Ideal Situation, and Practical Measures Toward Reaching the Ideal, Cochlear Implant Research Updates, Dr. Cila Umat (Ed.), ISBN: 978-953-51-0582-4, InTech, Available from: http://www.intechopen.com/books/cochlearimplant-research-updates/the-right-to-language-ethical-considerations-ideal-situation-and-practical-measurestoward-reachi

\section{INTECH}

open science | open minds

\section{InTech Europe}

University Campus STeP Ri

Slavka Krautzeka 83/A

51000 Rijeka, Croatia

Phone: +385 (51) 770447

Fax: +385 (51) 686166

www.intechopen.com

\section{InTech China}

Unit 405, Office Block, Hotel Equatorial Shanghai

No.65, Yan An Road (West), Shanghai, 200040, China 中国上海市延安西路65号上海国际贵都大饭店办公楼 405 单元

Phone: +86-21-62489820

Fax: +86-21-62489821 
(C) 2012 The Author(s). Licensee IntechOpen. This is an open access article distributed under the terms of the Creative Commons Attribution 3.0 License, which permits unrestricted use, distribution, and reproduction in any medium, provided the original work is properly cited. 